\title{
Response of the atmospheric hydrological cycle over the tropical Asian monsoon regions to anthropogenic aerosols and its seasonality
}

\author{
Hiroshi G. Takahashi ${ }^{1,2^{*}} \mathbb{D}$, Shingo Watanabe ${ }^{2}$, Makiko Nakata ${ }^{3}$ and Toshihiko Takemura ${ }^{4}$
}

\begin{abstract}
This study investigates the impact of anthropogenic aerosols on the atmospheric hydrological cycle over the tropical Asian monsoon region (South Asian, Southeast Asian, and western North Pacific monsoons), using a coupled atmosphere-ocean global climate model (CGCM), Model for Interdisciplinary Research on Climate-Earth System Models. Three-ensemble historical (HIST) and sensitivity (piAERO) experiments for the period 1985-2005 are conducted. The piAERO experiment is the same as HIST, but with anthropogenic aerosol emissions kept at preindustrial values. The results show that, as a whole, the Asian monsoon precipitation is reduced by the increase in aerosol loading during boreal summer and winter. This decrease in precipitation corresponds to a decrease in precipitable water due to the cooling in surface air temperature (SAT), mainly over adjacent oceans. The cooling is explained by the sum of the direct and indirect effects of aerosols. A modulation of the Walker circulation occurs, which can be explained by the east-west horizontal SAT gradient over the tropics due to the spatially heterogeneous increase in aerosols. Concurrent with the modulation of the Walker circulation, the anomalous descending motions over the tropical Asian monsoon region are consistent with the decrease in precipitation. In addition, the changes in local Hadley circulation (or a shift of the inter-tropical convergence zone) are unclear over the Asian monsoon region and thus cannot explain the decrease in precipitation. Moreover, the detailed spatial pattern of the response of the atmospheric hydrological cycle over the Asian monsoon region has distinct seasonality. Interestingly, signals are distinct in regions where tropical disturbance activity is vigorous during both boreal summer and winter. However, uncertainties regarding aerosol-cloud-precipitation interactions in current climate models and internal variability in the climate models may have affected the results.
\end{abstract}

Keywords: Atmospheric hydrological cycle, Asian monsoon, Aerosol, Cloud, Precipitation

\section{Introduction}

Although greenhouse gases (GHGs) cause global warming, aerosols cool the Earth's atmosphere. Many previous studies have investigated the global mean value of radiative forcing (e.g., IPCC 2013) and its effects on global climate. It is well known that the time-space distribution of aerosols is much more heterogeneous than that of GHGs, and therefore, the effects of aerosols on climate may vary over time and space. The effects of aerosols

\footnotetext{
*Correspondence: hiroshi3@tmu.ac.jp

'Department of Geography, Tokyo Metropolitan University, 1-1 Minamioosawa, Hachioji, Tokyo 192-0397, Japan

2Japan Agency for Marine-Earth Science and Technology (JAMSTEC), Yokohama, Japan

Full list of author information is available at the end of the article
}

are complex because they serve as the source of clouds and thus affect the atmospheric hydrological cycle. In this study, we define the atmospheric hydrological cycle as water vapor, clouds, and precipitation.

The effects of aerosols on global and regional climates can be attributed to two processes: aerosol-radiation interactions, also known as direct aerosol effects (e.g., Ming et al. 2005), and effects through cloud changes, also known as indirect aerosol effects or aerosol-cloud interactions (e.g., Lohmann et al. 2010). Estimates of these indirect effects have high degrees of uncertainty (e.g., Penner et al. 2006) and are still poorly understood (e.g., IPCC 2013).

Compared with the global-mean and zonal-mean impacts of aerosols, the regional impacts of aerosols on 
a climatological timescale are not well understood (e.g., Shindell et al. 2012). There are two major sources of anthropogenic aerosols over the Asian monsoon region, i.e., China and India. It is therefore possible that there are clear effects of aerosols. In addition, most studies have investigated the annual mean impact of aerosols. However, seasonal changes in atmospheric circulation can modify the spatial distribution of aerosols and their effects, particularly over the Asian monsoon region, which can have distinct seasonality. Thus, we focus on the tropical Asian monsoon region (South Asian, Southeast Asian, and western North Pacific monsoons).

In India, which is within the Asian monsoon region, a reduction in downward shortwave radiation at the surface (DSRS) due to a large atmospheric concentration of aerosols has been observed. This can result in decreased evaporation and summer rainfall (Ramanathan et al. 2005). The importance of dust and black carbon at the onset of the Indian summer monsoon has been evaluated based on observational data (Lau and Kim 2006). Bollasina et al. (2011) reported that the reduction in the Indian summer monsoon can be attributed primarily to anthropogenic aerosol emissions. These studies, however, focused on the Asian summer monsoon over India, whereas we examined aerosol effects over the entire Asian monsoon region during boreal summer and winter. Bollasina et al. (2011) suggested that the mechanism underlying the reduction in precipitation over India was the weakening of the meridional land-sea contrast with weakening of the local Hadley circulation due to the decrease in DSRS over India. However, changes in cloud cover due to an increase in aerosol burden were unclear in the previous studies, which can also change the DSRS. The effects of aerosols on the atmospheric hydrological cycle have not been investigated over the tropical Asian monsoon region other than India. This study focuses on the whole tropical Asian monsoon region.

The present study investigates how aerosols affect cloud cover and precipitation over the tropical Asian monsoon region through aerosol-radiation and aerosol-cloud interactions, including the coupling effects of the ocean-land-atmosphere climate system, using a coupled atmosphere-ocean global climate model (CGCM). We focused on the Asian monsoon region because aerosol emissions over this region are very high and are expected to increase in the future. In addition, it is possible that the distinct seasonal changes in low-level monsoon winds seasonally vary the spatial pattern of aerosols and their effects. Responses of cloud and precipitation to aerosols over the Asian monsoon region are also examined. The numerical experiment is described in the "Methods/Experimental" section, and the results of the impacts of aerosols on atmospheric hydrological cycle over the tropical Asian monsoon region are shown in the "Results" section. Uncertainties of the effects of aerosols are discussed in the "Discussion" section, and the "Conclusions" section is given.

\section{Methods/Experimental Numerical experiments}

To understand the impact of aerosols on regional and global climates, we used historical control experiments (HIST) for the 155-year period from 1851 to 2005, under the protocol for historical experiments of the Intergovernmental Panel on Climate Change-Fifth Assessment Report (IPCC-AR5; Taylor 2012). To clarify the effects of aerosols on the atmospheric hydrological cycle through both the aerosol-radiation and aerosol-cloud interactions, including slow responses, we used the Model for Interdisciplinary Research on Climate-Earth System Models (MIROC-ESM; Watanabe et al. 2011), a CGCM, coupled with the Spectral Radiation-Transport Model for Aerosol Species (SPRINTARS; Takemura et al. 2000; 2002). We performed sensitivity (pre-industrial aerosol; piAERO) experiments to estimate the effects of anthropogenic aerosols; these were the same as HIST, but with the emissions of anthropogenic aerosols fixed at their preindustrial (around 1850) values. The anthropogenic aerosols in our experiments are sulfates, organic carbons, and black carbons. The amount of black carbons is much smaller than that of the other anthropogenic aerosols although the effects of black carbons are quite different from those of the sulfates and organic carbons. We note that there are interannual and long-term variations in natural aerosols, such as dust and volcanic aerosols. We selected the analysis period of from 1976 to 2005 because the emission of anthropogenic aerosols has been increased until the end of the simulation period over the Asian monsoon region (e.g., Ohara et al. 2007). To reduce uncertainty in the simulation, we used three ensembles for each experiment. We used 90 seasonal means to calculate the 30 -year seasonal mean. The differences between HIST and piAERO experiments were evaluated using the two-sided Student's $t$ test at the $95 \%$ significance level.

\section{Observational datasets}

To confirm the low-level atmospheric circulation simulated in the HIST, we used the dataset of the Japanese 55-year Reanalysis Project (JRA-55; Kobayashi et al. 2015; http://jra.kishou.go.jp/JRA-55/index_en.html), including the surface zonal and meridional winds. We also used satellite-derived rainfall data from the Global Precipitation Climatology Project (GPCP; Adler et al. 2003; https://www.esrl.noaa.gov/psd/) for the 30-year period from 1980-2009; this dataset includes observed global monthly precipitation on a $2.5^{\circ} \times 2.5^{\circ}$ grid. We also used the 30-year climatology data from 1980 to 2009. Although the averaged period was slightly different from the period 
of the HIST simulations and the observations, we confirmed that this had a negligible effect on the findings. In addition, we used long-term variations of the observed SAT dataset, the Hadley Centre-Climatic Research Unit Version 4 (HadCRUT4; Morice et al. 2012), for validation.

\section{Results}

Impact of aerosols on global climate

This section focuses on the impact of aerosols on the global and regional climates, beginning with the global climate. The performance of the HIST simulation was investigated previously in Watanabe et al. (2011). The following subsection focuses on the reproducibility of the Asian monsoon precipitation, which is important for our purposes. Figure 1 presents the time series of global SAT, precipitation, aerosol optical depth (AOD), precipitable water, and cloud effective radius for the 100-year period from 1906 to 2005. To investigate long-term changes, seasonal components and those with periodicity of less than 10 years were suppressed by using a running mean with a window of 121 months.

It is well known that the global mean SAT has increased due to increased concentrations of GHGs, such as carbon dioxide. All three members of the HIST and piAERO experiments showed similar long-term increases (Fig. 1b), respectively. The simultaneous drops in SAT in the 1960s, around 1980, and around 1991 were considered to be caused by large volcanic eruptions, i.e., the effects of natural aerosols (Fig. 1a), although the drops were unclear due to the effect of the digital filter. These drops in SAT were also simulated in piAERO, as long-term changes in the natural aerosol burden were similar to those in HIST, although the simulated long-term trends in SAT in the piAERO were different from those in the HIST. Compared to the HIST, the increase in global mean SAT was
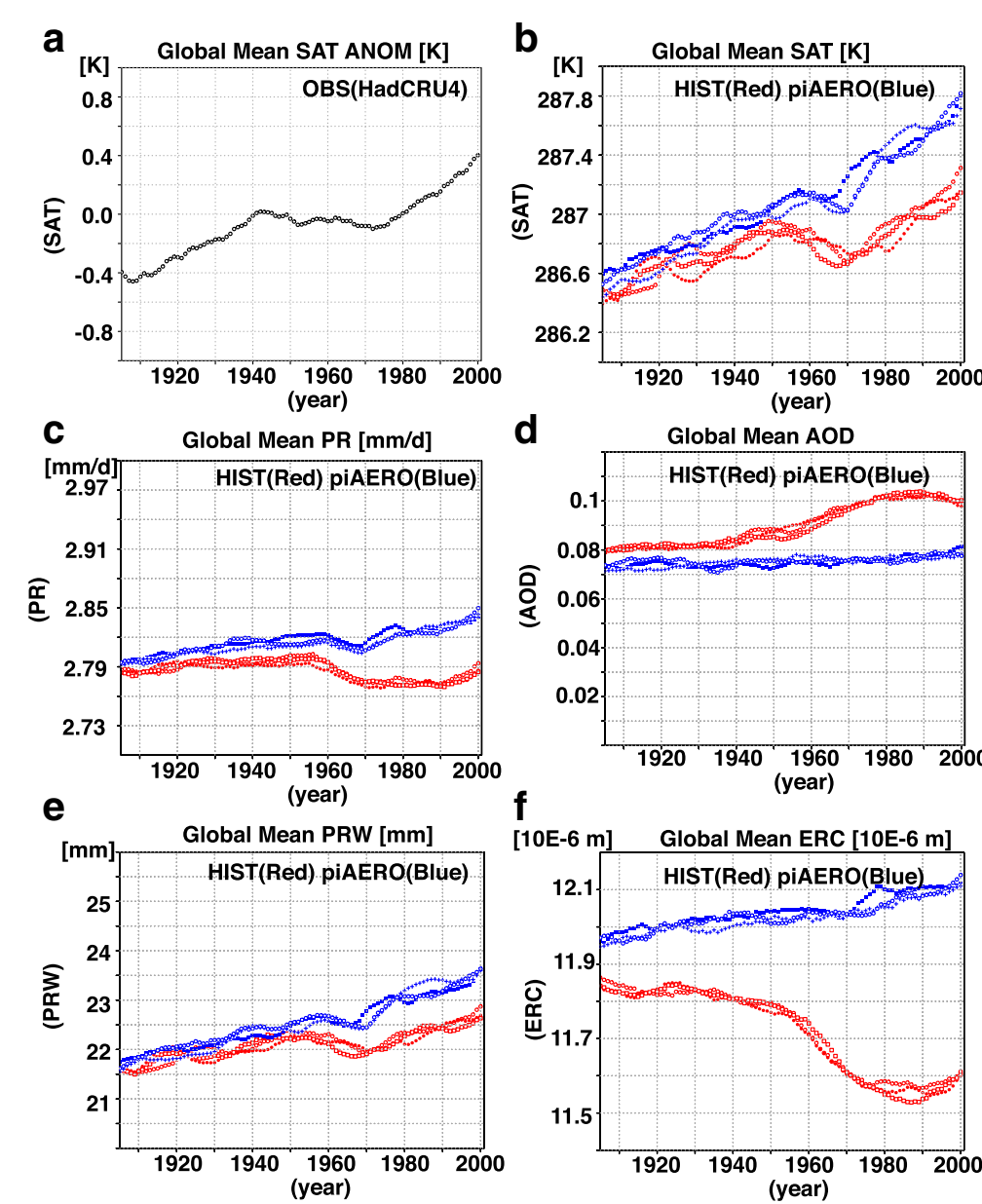

d

Global Mean AOD

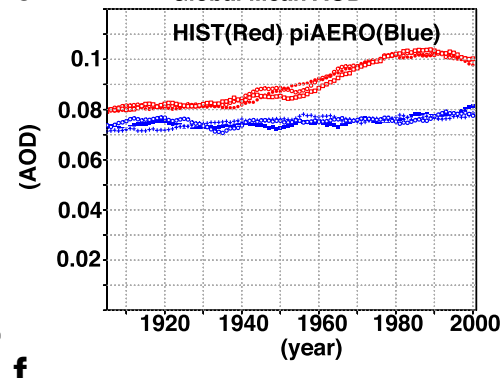

$\mathbf{f}$
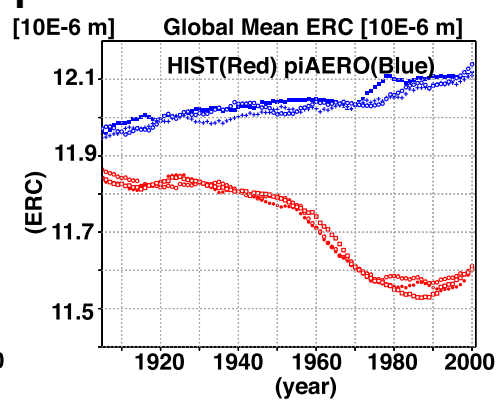

Fig. 1 a Observed time series of global mean surface air temperature (SAT) anomaly from the average of the period of 1961-1990. Simulated time series of the global mean $\mathbf{b}$ SAT, c precipitation, $\mathbf{d}$ aerosol optical depth (AOD), e precipitable water, and $\mathbf{f}$ effective radii of clouds in the three ensemble historical (HIST) and sensitivity (pre-industrial aerosol; piAERO) experiments. To examine the long-term trends, we used a 121-month running mean filter to remove seasonal and shorter interannual variations 
larger in piAERO after the 1950s. The timing (from 1955 to 2005) when the differences in global mean SAT between the HIST and piAERO has gradually become larger corresponded to that in AOD (Fig. 1d). The increase in AOD was due to human activity.

In our experiments, during 1905-2005, the global mean SAT increased by approximately $0.6-0.8 \mathrm{~K}$ in HIST and by approximately $1.0-1.2 \mathrm{~K}$ in piAERO. These simulations indicate that approximately one third to one half of the total increase in global mean SAT was likely suppressed by the increase in anthropogenic aerosol burden. This estimated sensitivity to global warming was greater than that seen in the multi-model results of the IPCC-AR5 (IPCC 2013).

We also examined changes in the atmospheric hydrological cycle. Concurrent with the long-term increase in SAT, over the 100-year period, the global mean precipitation and precipitable water increased in the piAERO experiments (Fig. 1c, e). In general, an increase in global mean SAT results in an increase in precipitation, due to an increase in the global mean precipitable water. However, the global mean precipitation in the HIST decreased after 1950, although the global mean SAT gradually increased. The HIST and piAERO simulations of long-term changes in the global mean cloud effective radius showed clear differences between the HIST and piAERO (Fig. 1f). Smaller cloud effective radii occurred under higher aerosol loading conditions. These results can be explained by the cloud lifetime effects of aerosols (e.g., Twomey et al. 1984; Albrecht 1989).

\section{Reproducibility of the Asian monsoon precipitation and circulation}

Before discussing the regional characteristics and seasonality of the aerosol impacts, we examined the reproducibility of precipitation over the Asian monsoon region. Figure 2 presents the climatology based on observations from GPCP and JRA55 and simulations from MIROC-ESM.

The simulation revealed spatial peaks in precipitation during boreal summer (June, July, August; JJA) over the Asian monsoon region (Fig. 2b), similar to the observations (Fig. 2a). However, a major peak in precipitation was simulated over the western coast of the Indian subcontinent while this was observed over the western coast of the Indochina Peninsula. In addition, compared to the observations, weaker monsoon westerlies and a weaker monsoon trough around the Philippines were found in
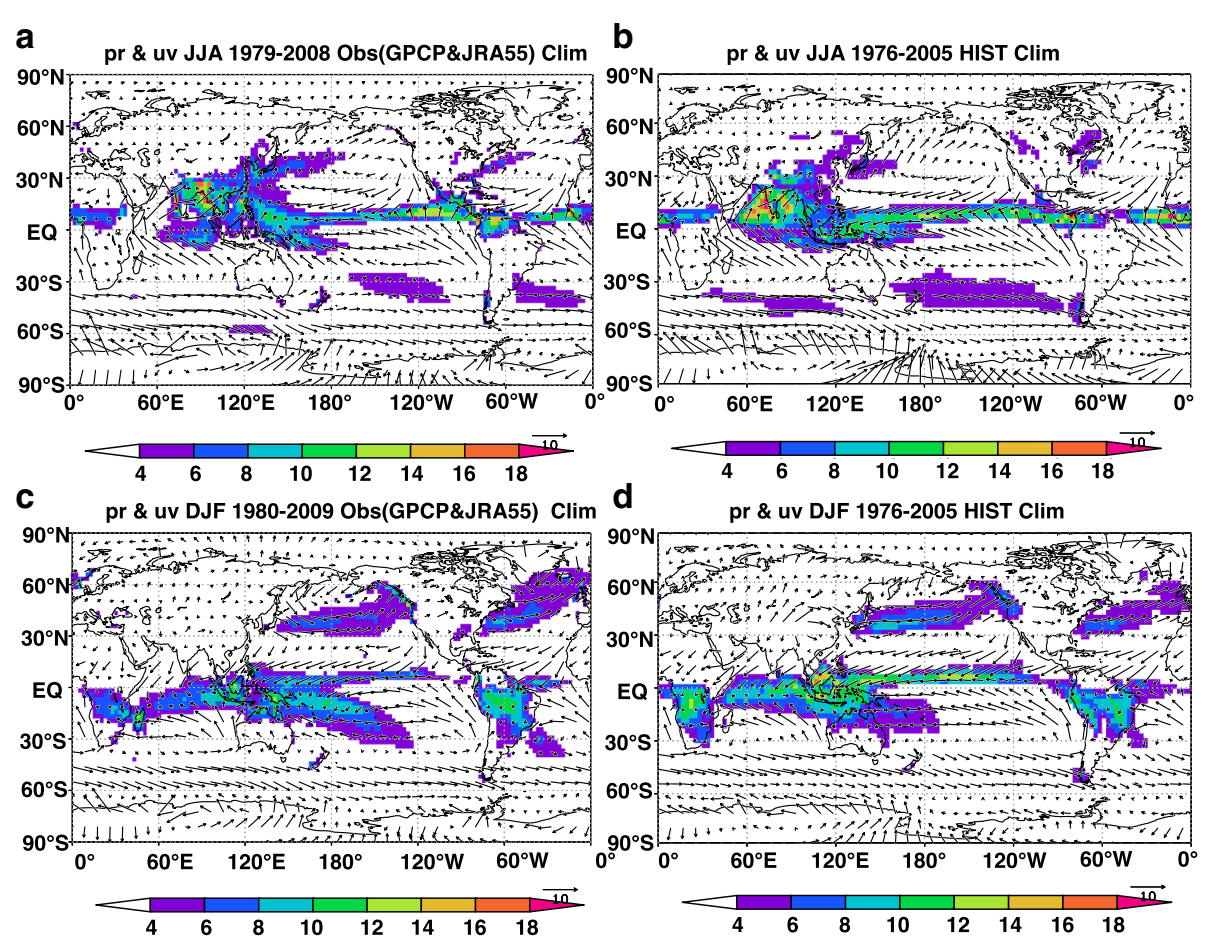

Fig. 2 Climatology in a observed and $\mathbf{b}$ simulated precipitation and surface winds at $10 \mathrm{~m}$ above the surface during June, July, and August (JJA). c and $\mathbf{d}$ are the same as $\mathbf{a}$ and $\mathbf{b}$, respectively, except for December, January, and February (DJF). For the observations, the values were averaged over 30 years from 1979 to 2008, and for the HIST simulation, the values were averaged over 30 years from 1976 to 2005. For the simulated climatology, we averaged the three-ensemble members 
the HIST experiments. Precipitation over the southern Maritime Continent was also overestimated in HIST.

During boreal winter, although the simulation reproduced the spatial distribution of precipitation and circulation, the precipitation over the equatorial Indian Ocean was greater in HIST than that in the observations. As in simulations of boreal summer, precipitation over the southern Maritime Continent was overestimated, and precipitation over the southern Pacific Ocean was underestimated in HIST.

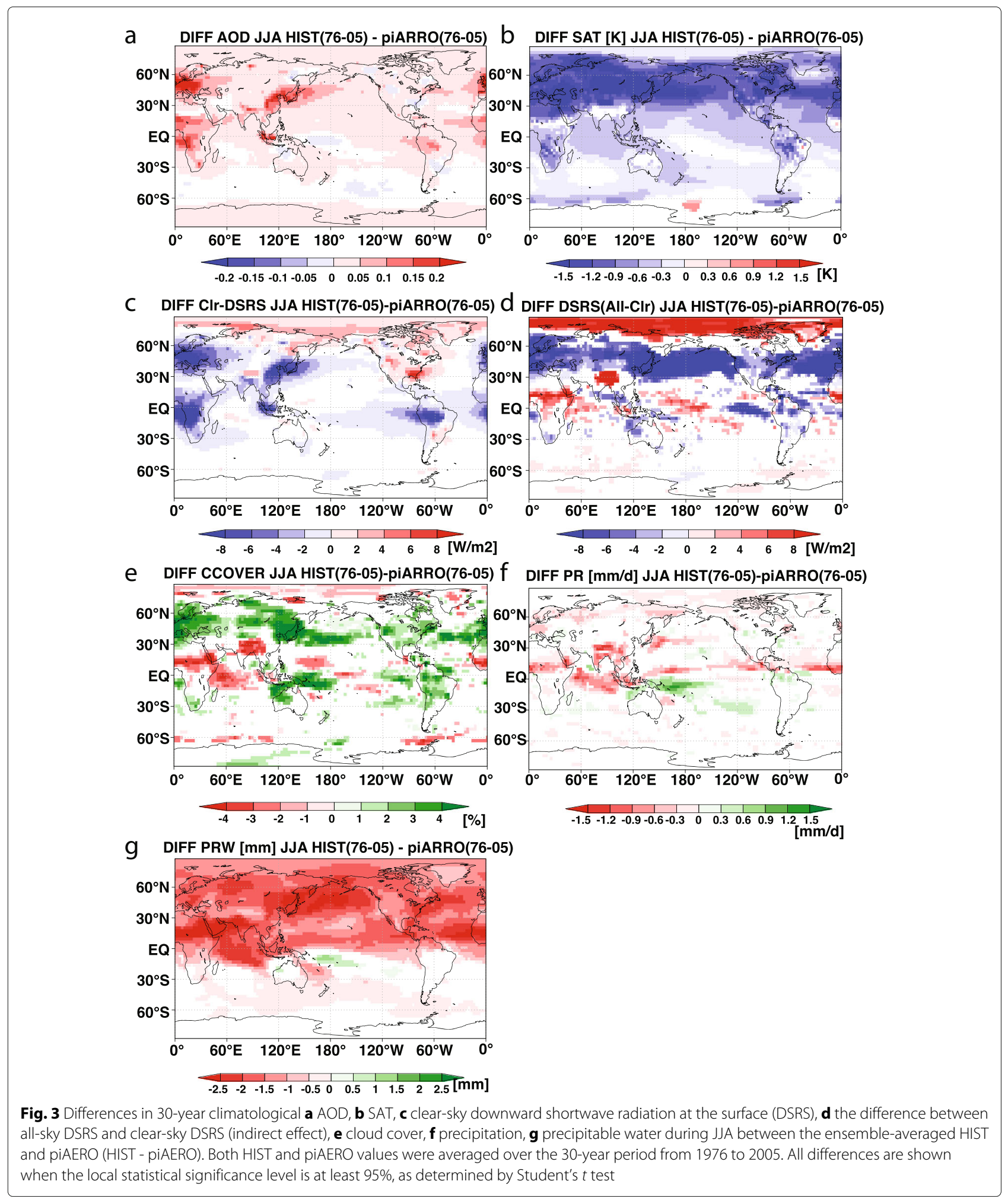


Although there were some differences between simulated and observed precipitation, the general features and spatial patterns of precipitation and low-level circulation and their seasonal changes were reproduced by HIST.

\section{Impact of aerosols during boreal summer (JJA) Geographical pattern of AOD changes}

To understand how aerosols affect the regional climate of the tropical Asian monsoon, we produced a global map of differences between the HIST and piAERO in AOD, SAT, clear-sky downward DSRS, the difference between all-sky and clear-sky DSRSs, cloud cover, and precipitation (Fig. 3). Because changes outside of the tropical Asian monsoon region may affect the regional climate of the tropical Asian monsoon region, we analyzed the changes globally, focusing on the tropical Asian monsoon region. The difference between all-sky and clear-sky DSRSs will be explained later. To detect statistically significant signals, we used all three ensembles in both experiments.

An increase in AOD during JJA was observed over and around the regions of East Asia, South Asia, Maritime Continent, Western Europe, Western Africa, and South America (Fig. 3a). The signal of AOD was weaker over North America because the timing of improvement air quality problems was different from the other regions. During the period considered, considerable changes have occurred in land use, such as deforestation, conversion from natural vegetation to cropland, and urbanization.

The major source regions of aerosols are located in the Northern Hemisphere. Over this study region of the Asian monsoon, China and India are the major source regions. The aerosols were partly transported downstream of the monsoon flows (see Fig. 2). Notably, over the South Pacific Ocean, there is no major source of aerosols, which induced the meridional contrast of AOD globally, particularly over the Pacific Ocean. The increase in AOD ranged from 0.05 to 0.20 .

\section{Surface air temperature response}

Over the tropics, statistically significant cooling signals were simulated over the entire Indian Ocean, North Pacific Ocean, and the North Atlantic Ocean (Fig. 3b). Note that the tropical South Pacific Ocean was not cooled by the increase in aerosols. Thus, the east-west interoceanic contrast in SAT between the Indian Ocean and Western Pacific Ocean was dominant (Fig. 3b), which may have affected the atmospheric hydrological cycle of the tropical Asian monsoon. In addition, no clear SAT signals were simulated over the Asian monsoon land regions, i.e., the Indian subcontinent and the Indochina Peninsula, indicating that the cooling over land was not systematically simulated. Cooling signals were also simulated over the middle and high latitudes in the Northern Hemisphere (Fig. 3b), whereas less cooling was simulated over the Southern Hemisphere. Notable cooling was simulated over a zonal band from $30^{\circ} \mathrm{N}$ to $70^{\circ} \mathrm{N}$ and not only near the source regions of aerosols.

Due to the increases in AOD, negative signals in clearsky DSRS were observed over the major source regions (Fig. 3c). The spatial distributions of the differences in AOD and clear-sky DSRS were similar, indicating that direct radiation effects resulted in cooling over the major sources of aerosols. However, the changes in clear-sky DSRS due to increased AOD (Fig. 3c) cannot explain all of the changes in SAT (Fig. 3b).

\section{Changes in cloud cover and precipitation}

To understand the changes in SAT, we also examined the indirect effects of aerosols by considering changes in cloud cover, which are the parts of the atmospheric hydrological cycle. Of course, we also considered the responses of precipitation and precipitable water. Here, we defined the indirect effects of the aerosols as the difference between the all-sky and clear-sky DSRS (following Mukai et al. 2008; Mukai and Nakajima 2009). For this estimation, the indirect effects were considered to be the changes in cloud cover due to different aerosol conditions. However, this is not simply a sum of the first and second indirect effects; it involves many effects related to changes in the aerosol conditions, so we cannot estimate only the indirect effects of aerosols.

An impact of cloud cover changes on the decrease in SAT due to aerosol-cloud interactions was clear over the tropical regions, such as equatorial Indian Ocean, equatorial Western Pacific, and the Indian subcontinent (Fig. 3d), although significant cooling over the mid-latitudes was also simulated over downstream regions of the aerosol sources. We confirmed that changes due to the indirect effects could be explained by changes in cloud cover because their spatial patterns were similar (Figs. 3d, e). It is noteworthy that the effects of clouds due to the changes in aerosol condition contributed significantly to the creation of inter-oceanic and inter-hemispheric contrasts in SAT over the tropical Asian monsoon region and the Pacific Ocean.

Changes in precipitation were remarkable primarily over the tropical regions (Fig. 3f). An increase in precipitation was simulated over part of the Maritime Continentsouthern equatorial Pacific and Amazon regions, whereas a decrease was observed over the Asian monsoon land, the southern equatorial Indian Ocean, and Central Africa. The changes in precipitation can be explained by changes in water vapor (Fig. 3g). The changes in water vapor mostly corresponded to those in SAT. The decreases in water vapor were simulated over the entire Asian monsoon region and the Indian Ocean. Only the equatorial South Pacific Ocean showed a positive signal in water vapor. 


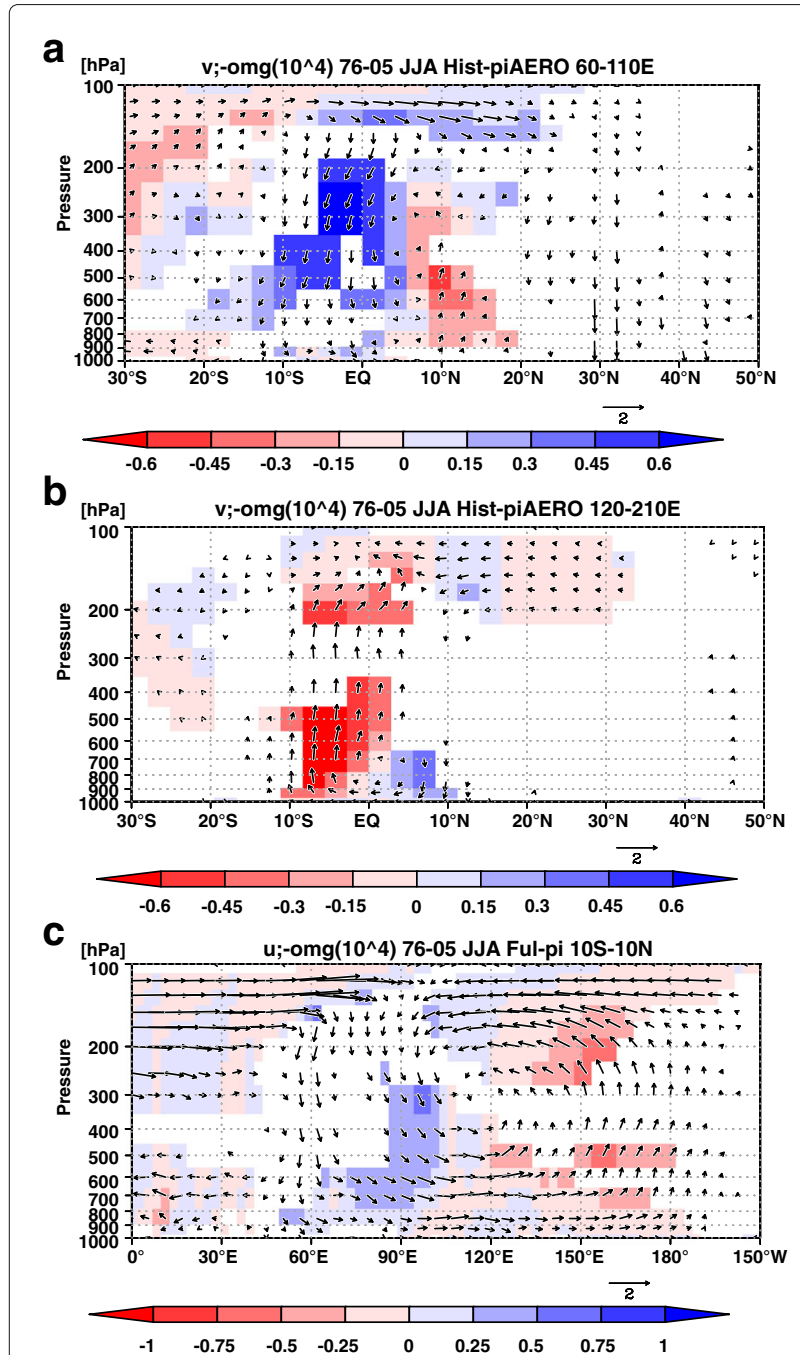

Fig. 4 a Latitude-vertical (in pressure) cross-section in meridional and vertical winds over the Asian monsoon region $\left(60^{\circ} \mathrm{E}-110^{\circ} \mathrm{E}\right)$ during JJA. b Same as Fig. $5 a$, but over the Pacific Ocean $\left(120^{\circ} \mathrm{E}-150^{\circ} \mathrm{W}\right)$ during JJA. c Longitude-vertical (in pressure) cross-section in zonal and vertical winds along the equator $\left(10^{\circ} \mathrm{S}-10^{\circ} \mathrm{N}\right)$ during $\mathrm{JJA}$. As we used $\omega$, we multiplied $\omega$ by -1 for vectors to understand vertical motions. The plotted vectors are statistically significant for horizontal or vertical components, or both. The red (blue) color indicates ascending (descending) motion. The unit of zonal and meridional winds is $\mathrm{m} \mathrm{s}^{-1}$. The unit of $\omega$ is $10^{-4} \mathrm{~Pa} \mathrm{~s}^{-1}$. The plotted colors are statistically significant for the vertical component

\section{Changes in atmospheric circulation and coupling with clouds and precipitation}

To understand the changes in meridional and zonal circulation on the Asian monsoon regional scale, we produced meridional-vertical cross-sections of winds over the Asian monsoon region and the Pacific Ocean, and a zonal-vertical cross-section of winds along the equatorial region (Fig. 4). To associate atmospheric circulation changes with the precipitation changes, we analyzed zonal and meridional averaged changes in precipitation (Fig. 5).

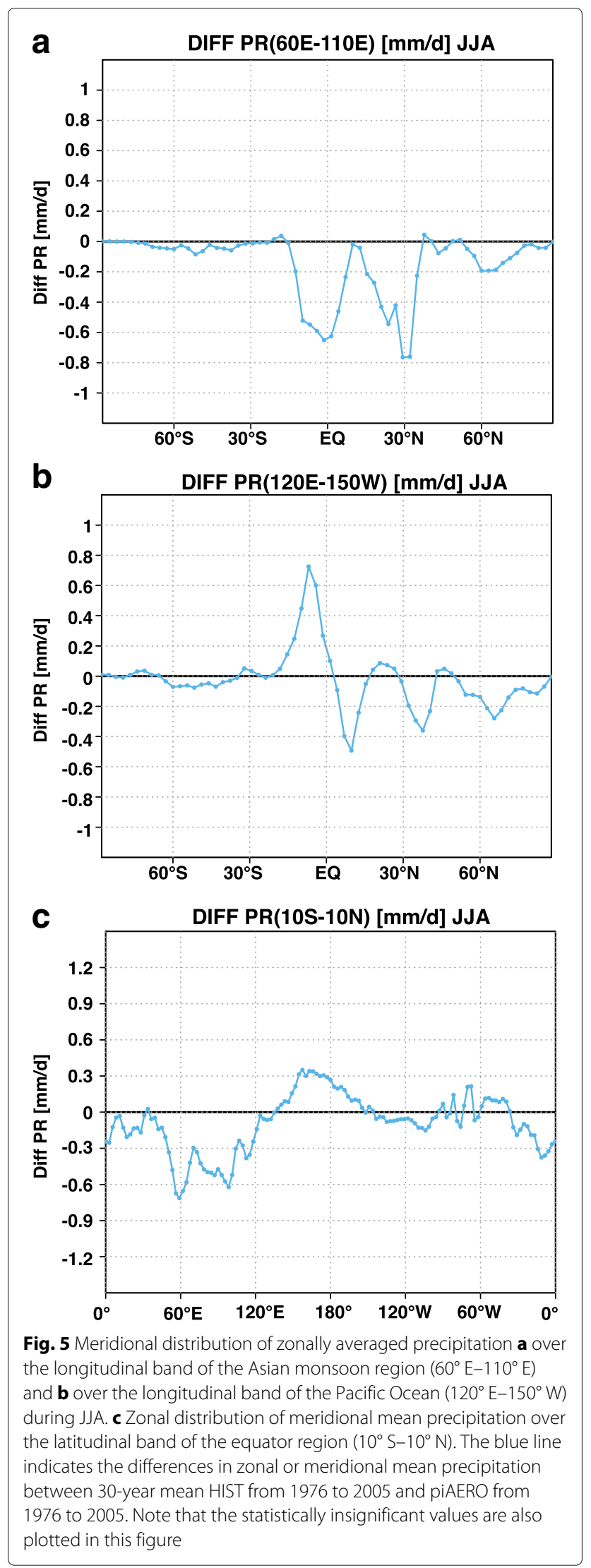


Over the Asian monsoon region, anomalous descending motions were simulated south of the equator and along the zonal band of $25-35^{\circ} \mathrm{N}$ (Fig. 4a), consistent with the decreased cloud cover and precipitation (Figs. 3e, $\mathrm{f}$ and 5a). These results revealed no changes in local Hadley circulation over the Indian Subcontinent and the Indochina Peninsula (along the zonal band of $10-25^{\circ} \mathrm{N}$ ), which is different from the finding of Bollasina et al. (2011). A weak enhancement of local Hadley circulation over the Asian monsoon region was simulated within $10^{\circ} \mathrm{S}-10^{\circ} \mathrm{N}$, which did not cover the Asian landmass (Fig. 4a). Over the Pacific Ocean, only the anomalous ascending motions were simulated over the equatorial regions (Fig. 4b), which is consistent with the changes in precipitation (Fig. 5b). The anomalies in the equatorial zonal circulation showed an eastward shift of the convective center of the Walker circulation or enhancement of the Walker circulation over the Indian-Pacific trans-ocean sector (Fig. 4c), which is consistent with the changes in precipitation (Fig. 5c). This suggested that the changes in equatorial zonal circulation can more coherently explain the large-scale anomalies in cloud cover and precipitation than can changes in local Hadley circulation. The distinct changes in the Walker circulation can be confirmed by the spatial map of surface winds (Fig. 6). These anomalous descending (ascending) motions were consistent with the decreases (increases) in cloud cover and precipitation, making it difficult to determine the causeeffect relationship between the cloud-precipitation and circulation changes.

On the more detailed spatial pattern of the precipitation response, the Asian summer monsoon precipitation decreased along two zonal bands, $10^{\circ} \mathrm{S}$ to the equator and $20^{\circ}-30^{\circ} \mathrm{N}$ (Figs. 3f and 5a). Concurrent with the decreases in precipitation over the Asian monsoon region, an anomalous divergence in surface winds over the equatorial Indian Ocean and an anomalous anti-cyclonic circulation over South Asia and the Tibetan Plateau were simulated (Fig. 6). In addition, an increase in precipitation over the equatorial Pacific was consistent with an anomalous convergence in surface winds. Strong westerly anomalies over the eastern Indian Ocean and Maritime Continent, which modulated the Walker circulation in this region, were simulated. The precipitation signals also corresponded to the anomalous vertical motions (Fig. 4a). This spatial precipitation pattern matched the observed pattern of interannual precipitation variability, i.e., a zonally extended striped pattern (monsoon trough), as indicated in previous observational studies (e.g., Goswami and Mohan 2001; Fujinami et al. 2011; Takahashi et al. 2015). The spatial pattern in precipitation is associated with the tropical cyclone activity (Takahashi et al. 2015; Takahashi and Yasunari 2006), which suggests that the signal is associated with a modulation of tropical cyclone activity. The decrease in precipitable water (Fig. $3 \mathrm{~g}$ ) can weaken lowlevel water vapor convergence, even if the strength of wind convergence by a tropical disturbance does not change, and may reduce the development of tropical disturbances along the monsoon trough.

\section{Impact of aerosols during boreal winter (DJF) Geographical pattern of changes in AOD}

An increase in AOD during December, January, and February (DJF) was simulated over and around East Asia, Southeast Asia, Western Europe, Western Africa, and North America (Fig. 7a). Over the tropical Asian monsoon region, there were large differences in AOD between JJA and DJF over the eastern region of Eurasia. Although the major sources of aerosols were similar to those during boreal summer, AOD was greater over Southeast Asia and was lower over the mid-latitude North Pacific, compared with those during boreal summer. The differences in spatial distribution of AOD can be explained by the increase in local biomass burning (e.g., van der Werf et al. 2008) over Southeast Asia and by equatorward transportation of the East Asian aerosols due to the climatological winter monsoon winds in the lower troposphere, which contribute to the stronger zonal contrast in AOD between the Indian Ocean-Maritime Continent sector and the equatorial Pacific Ocean in boreal winter.

\section{Surface air temperature response}

Over the tropics, cooling was simulated over the tropical Indian Ocean, North Pacific Ocean, and tropical Atlantic Ocean. No clear cooling was simulated over the South Pacific Ocean. This SAT response results in an enhancement of the zonal gradient in SAT due to the increased aerosols (Fig. 7b), consistent with the spatial pattern of AOD (Fig. 7a). These features were similar to those in boreal summer. In addition, cooling in the mid-latitudes was weaker than that in boreal summer, which was consistent with a seasonal change in AOD.

Next, we investigated the aerosol-radiation interaction. Figure 7c shows the differences in clear-sky DSRS during DJF. There was noticeable cooling along the southeastern coast of Eurasia, which corresponded to AOD changes (Fig. 7a). Again, although the geographical pattern of the changes in SAT was not entirely explained by the direct effect of aerosols due to the increased AOD, the sum of direct and indirect effects (Fig. 7c, d) can explain the changes in SAT. It was found that the spatial pattern of cloud cover was similar to that of indirect effects of aerosols. Moreover, the spatial distribution of the indirect effects (Fig. 7d) was different from that seen during JJA (Fig. 7d). The simulated cooling in the mid-latitudes due to the indirect effects of aerosols over the North Pacific Ocean at around $30^{\circ} \mathrm{N}$ was weaker than that in boreal summer. 


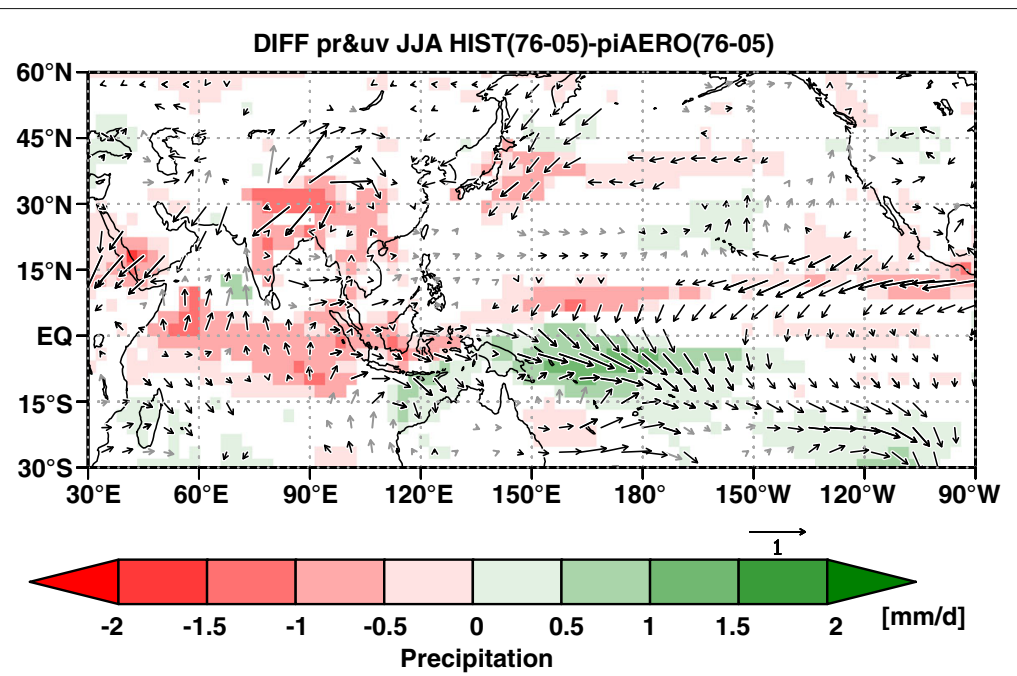

Fig. 6 As in Fig. 3, but for precipitation (color) and $10 \mathrm{~m}$ surface horizontal winds (vector) during JJA. The unit of precipitation (wind) is mm day ${ }^{-1}$ $\left(\mathrm{m} \mathrm{s}^{-1}\right)$. Gray vectors represent the spatial pattern of differences in wind, which are not statistically significant. Only stronger differences $\left(>0.2 \mathrm{~m} \mathrm{~s}^{-1}\right)$ are plotted

\section{Changes in cloud cover and precipitation}

During DJF, east-west contrasts in cloud cover and precipitation were simulated over the tropics (Fig. 7e, f), corresponding to the stronger zonal gradient in SAT and precipitable water over the Indian Ocean and western Pacific Ocean (Fig. 7b, g). Decreases in precipitable water were simulated over the entire tropical region except for the tropical South Pacific Ocean, which can almost entirely explain the decrease in precipitation over the tropical Asian monsoon region. Although the spatial patterns of cloud and precipitation during DJF were somewhat different from those during JJA, the dominant east-west contrasts in cloud cover and precipitation were similar between boreal summer and winter.

Moreover, there were different responses of cloudprecipitation between the tropics and mid-latitudes. In the mid-latitudes, the cyclonic anomalies and enhancement of the winter monsoon outflows over and around Japan were associated with an increase in cloud cover and a decrease in precipitation (Figs. 7 and 8). This response can be explained as the well-known lifetime effect of aerosols. Interestingly, the signs of changes in precipitation corresponded to those of changes in cloud cover over the tropics (Figs. 3 and 7), which were different from the responses in the mid-latitudes. The different responses are discussed in the "Uncertainties of effects of aerosols on climate" section.

\section{Changes in atmospheric circulation and coupling with clouds and precipitation}

This subsection discusses changes in cloud cover and precipitation during boreal winter, which are associated with atmospheric circulation. Takahashi and Watanabe (2016) reported that the decreased volcanic sulfate aerosols caused partial enhancement of trade winds over the equatorial western Pacific Ocean from 1991 to 2010, which can be explained by the zonal gradient in SAT. Their study showed that an aerosol forcing can change the largescale circulation over the tropics, although the forcing of aerosols in our experiment is quite different from that in Takahashi and Watanabe (2016). The differences can be clearly seen from the spatial pattern of SAT. Furthermore, a few observational studies showed co-variability of the aerosol-cloud-precipitation over and around the Maritime Continent on interannual timescales (e.g., Yamaji and Takahashi 2014).

As with the boreal summer, we investigated changes in meridional and zonal circulation (Fig. 9) and changes in precipitation for winter (Fig. 10). The changes in the local Hadley circulation over the Asian monsoon region were not clear (Fig. 9a). Over the Asian monsoon region, anomalous descending motions (Fig. 9a) were consistent with the decreased precipitation (Fig. 10a). Over the Pacific Ocean, anomalous ascending motions were consistent with the increase in precipitation (Figs. 9b and 10b), which can be understood as the southward shift of the inter-tropical convergence zone (ITCZ). In addition, this southward shift of the ITCZ (Figs. 7 and 10) was partly consistent with the annual mean response simulated by Takemura et al. (2005). However, we found that the responses over the Asian monsoon region and the Indian Ocean were quite different.

Changes in the Walker circulation were dominant (Fig. 9c). The anomalous convective center of the Walker circulation was simulated over the western equatorial Pacific Ocean, and this distinct signal was statistically 


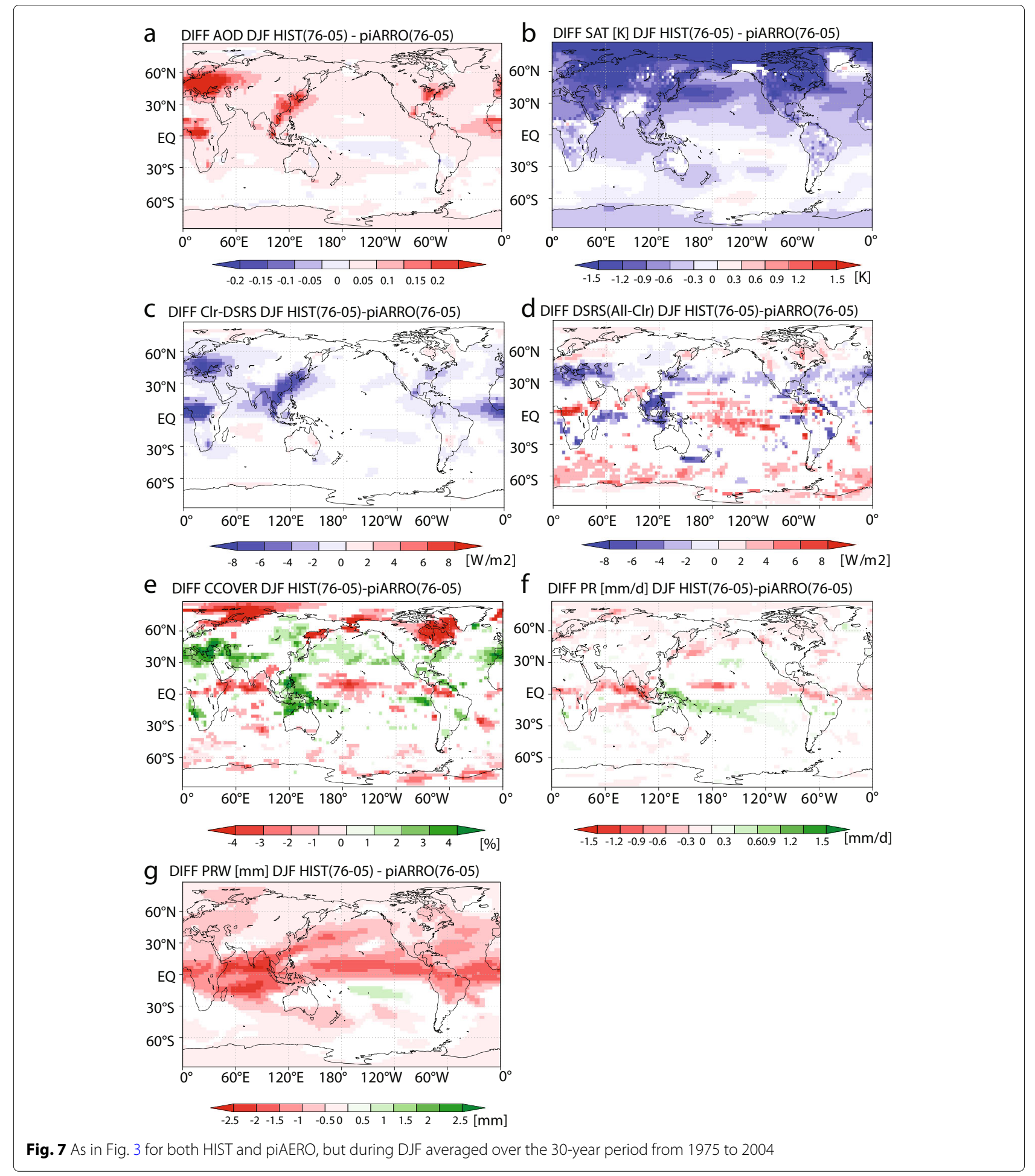

significant (Fig. 9c and 10c). Thus, changes in part of the Walker circulation, rather than in local Hadley circulation, were strongly coupled with the changes in precipitation over the tropical Asian monsoon region. Note that our results regarding changes of the Walker circulation coupling with cloud and precipitation in association with the changes in zonal gradient of SAT can be explained in a similar manner to Takahashi and Watanabe (2016). Nevertheless, the changed spatial patterns of precipitation, circulation, and SAT are different because of differences in experimental design, such as the treatment of forcing. 


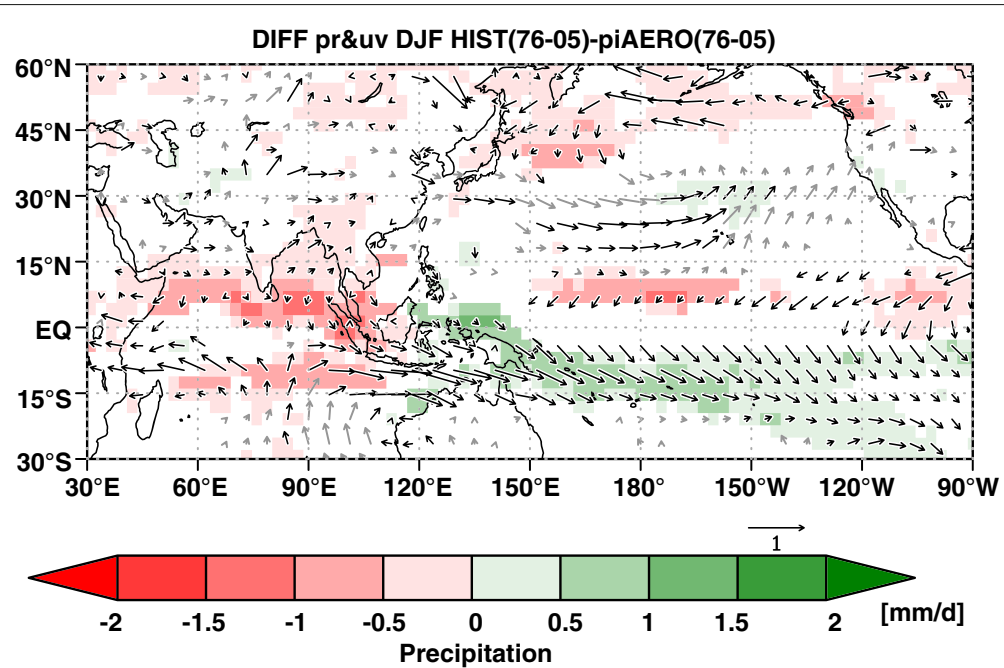

Fig. 8 As in Fig. 6, but during DJF. The unit of precipitation (wind) is $\mathrm{mm} \mathrm{day}^{-1}\left(\mathrm{~m} \mathrm{~s}^{-1}\right)$. Gray vectors represent the spatial pattern of differences in wind, which are not statistically significant. Only stronger differences $\left(>0.2 \mathrm{~m} \mathrm{~s}^{-1}\right)$ are plotted

The simulated decreases in cloud cover and precipitation coupled with increased aerosols over the Indian Ocean and Asian monsoon regions were symmetric with respect to the equator (Figs. 7e, f and 10a). The spatial pattern of this symmetrical response along $10^{\circ} \mathrm{S}$ and $10^{\circ} \mathrm{N}$ over the Indian Ocean corresponded to that of the activity of cyclone pairs that are symmetrical with respect to the equator (e.g., Kiladis and Wheeler 1995; Compo et al. 1999; Ito and Satomura 2009, Takahashi et al. 2011). The activity of cyclone pairs is dominant in this season. This correspondence suggests that modulation of the activity of the tropical disturbances may explain the decrease in cloud cover and precipitation. The decrease in precipitable water (Fig. $7 \mathrm{~g}$ ) due to cooling of the SAT (Fig. 7b) and anomalous descending motions (Fig. 9a, c) can weaken the low-level convergence of water vapor and/or the activity of the tropical disturbances over the equatorial Indian Ocean. Notably, the signals were clear along the major route of the tropical disturbances. These characteristics were common to both boreal summer and winter, although the frequent passage routes of tropical disturbances are different between boreal summer and winter.

\section{Discussion}

\section{Uncertainties of effects of aerosols on climate}

The previous sections discussed the changes in atmospheric hydrological cycle over the Asian monsoon region. Similar results were also simulated in previous studies. However, as important uncertainties in the effects of aerosols were found in the model experiments, this subsection focuses on two major uncertainties, namely, the aerosol-cloud-precipitation interactions and internal climate variability.
The differences between the mid-latitudes and the tropics in terms of the cloud-precipitation response to increased aerosols can be explained by differences in the total water vapor path. In the tropics, much more water vapor is available for the development of clouds and precipitation. In contrast to the mid-latitudes, the much reduced level of water vapor suppresses the development of clouds and precipitation, which can be understood as the cloud lifetime effect of aerosols.

However, the indirect effects of the aerosol-cloudprecipitation interaction in current climate models are strong compared to the observations (Michibata et al. 2016). Golaz et al. $(2011,2013)$ reported that the indirect effects in their Geophysical Fluid Dynamics Laboratory (GFDL) model was very sensitive to model turning, and the model simulated strong cooling by the indirect effects of aerosols. The response of clouds to aerosols is quite important, and it can change the sign of the SAT response. An increase in aerosols contributes to SAT cooling through a direct effect. This response may contribute significantly to the weakening of the land-sea contrast over the South Asian monsoon region (e.g., Bollasina et al. 2011). However, the decrease in cloud cover as indirect effects contributes to an increase in DSRS, which can change the sign of the response. This uncertainty may change the response of the Asian monsoon to aerosol forcing, including our current results.

\section{Internal climate variability of the Asian monsoon}

The inter-ensemble spread of the changes in precipitation over India was not small (supplemental figures in Bollasina et al. (2011)). The strong association with observed changes can be explained by the aerosol forcing or internal climate variability of the climate system. In 


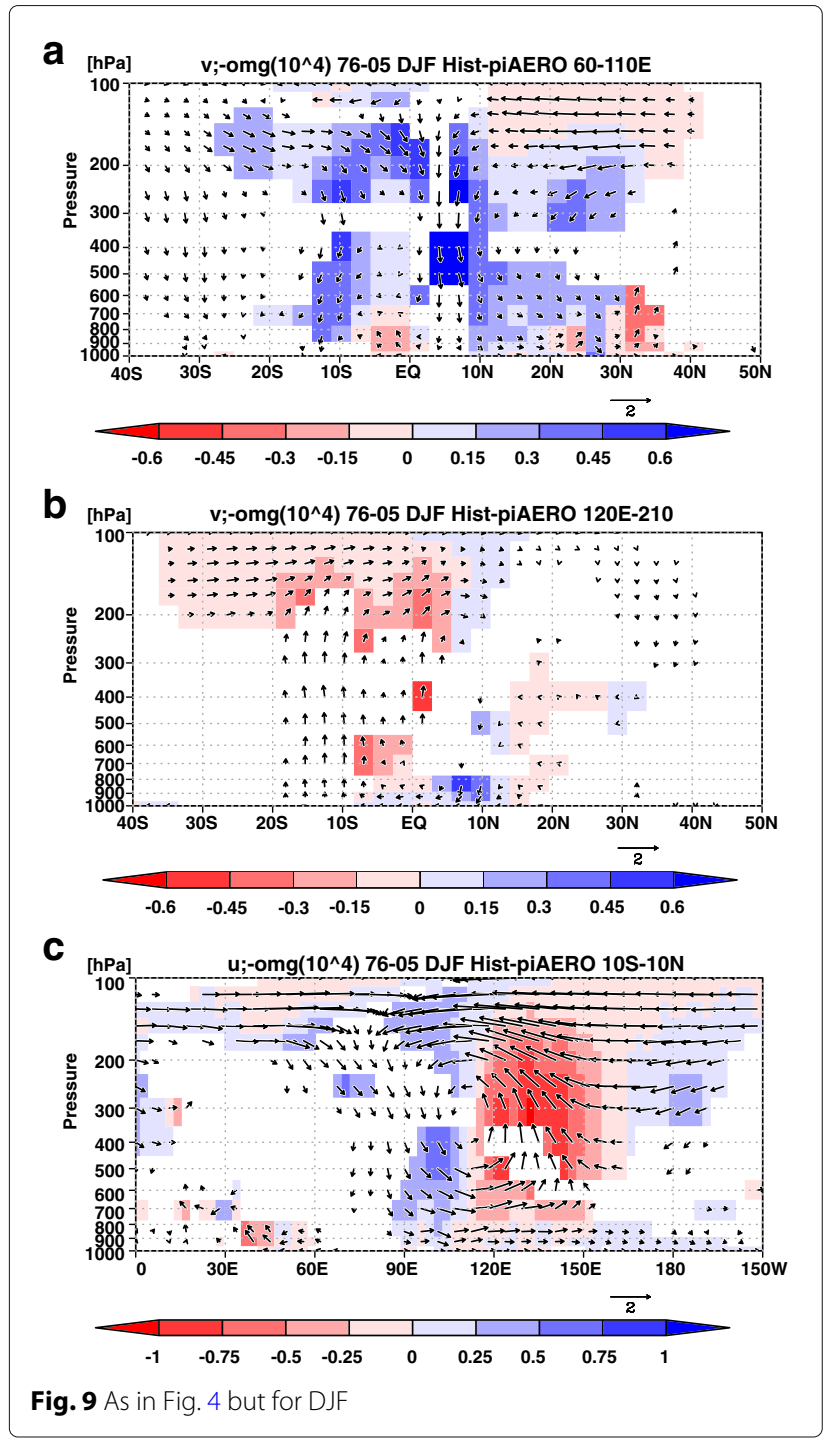

their three-ensemble experiments designed to understand the impact of aerosols (GHGs), Bollasina et al. (2011) reported that one ensemble member showed a slight increasing trend (decreasing trend), whereas the threeensemble mean exhibited a decreasing (increasing) trend. These results suggest that the internal climate variability of South Asia was not negligible, although the decreasing trends in precipitation found in multiple observational datasets were reliable. In terms of the interensemble spread in our experiments, the results showed that the changes in precipitation over the Asian monsoon region and changes in the meridional SAT gradient showed the same sign, respectively, although we should have increased the number of ensemble members, to strengthen this conclusion. In addition, Salzmann et al. (2014) supports a possible effect of internal variability on the observed trend in precipitation over South
Asia, based on analysis of the Coupled Model Intercomparison Project Phase 5 (CMIP5) dataset. To determine whether aerosol forcing or internal climate variability can explain the decrease in precipitation over the Asian monsoon region, including our current results, many ensemble experiments may be needed in future studies. However,

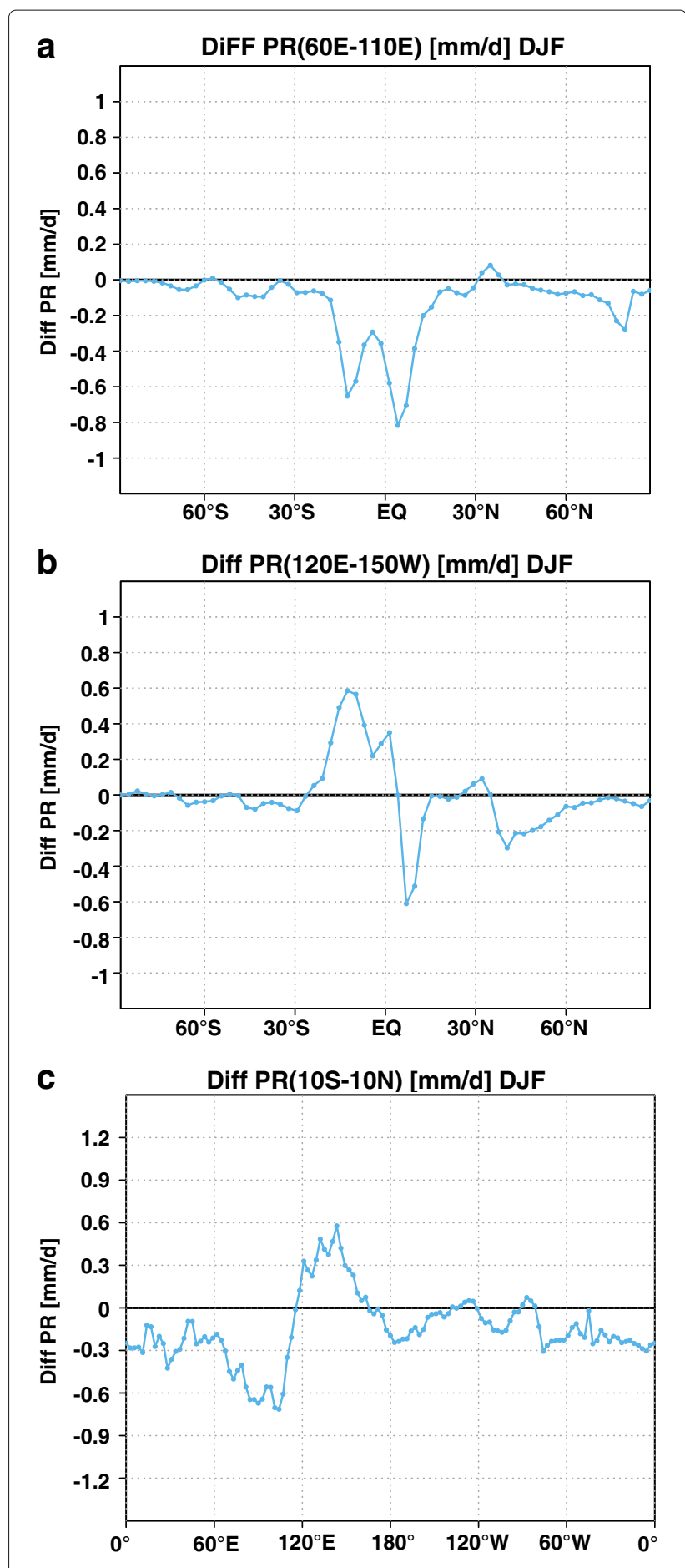

Fig. 10 As in Fig. 5, but for DJF 
this approach can only clarify responses of cloud and precipitation to an increase in aerosols in a current CGCM, which cannot essentially improve the understanding of the processes of aerosol-cloud-precipitation interactions. Therefore, both uncertainties should be improved by different approaches.

\section{Conclusions}

This study used a CGCM to investigate the effects of increases in aerosols during the period from the preindustrial era to the present. Three-ensemble historical (HIST) and sensitivity experiments (piAERO) were conducted for a 156-year period (1850-2005). The parameters of piAERO were the same as those for HIST, except that the emissions of anthropogenic aerosols were kept at preindustrial values.

The results showed that precipitation decreased over the tropical Asian monsoon region during both summer and winter. This decrease in precipitation corresponded to a decrease in precipitable water due to the cooling in SAT mainly over the adjacent oceans. The cooling was explained by the sum of the direct and indirect effects of aerosols. In addition, the decrease in precipitation over the Indian Ocean/Asian monsoon region, coupled with the increase over the Maritime Continent/western South Pacific, is likely associated with changes in the Walker circulation over the eastern Indian Ocean, Maritime Continent, and western Pacific Ocean. As a part of the Walker circulation, the anomalous vertical motions were consistent with the changes in precipitation. The modulation of the Walker circulation can be explained by the east-west horizontal SAT gradient between the Indian Ocean/Asian monsoon region and the Maritime Continent/western South Pacific due to heterogeneous increases in aerosols.

A southward shift of the ITCZ was simulated only over the equatorial Pacific Ocean particularly in boreal summer and winter, which can also be explained by the meridionally asymmetrical SAT response to aerosols. It was found that the changes in local Hadley circulation were not clear over the Asian monsoon region, which cannot explain the decrease in precipitation over the tropical Asian monsoon region.

The detailed spatial patterns of the decrease in precipitation over the Asian monsoon region were simulated. Interestingly, a decrease in precipitation was found along the major routes of the convectively coupled tropical disturbances in both boreal summer and winter, although the routes vary seasonally.

In this and related previous studies, cloud and precipitation responses to aerosols showed non-negligible uncertainty, particularly in the tropics. Changes in the simulated response of cloud and precipitation due to model uncertainty can be considered as major sources of uncertainty.
Therefore, additional studies are required to gain a better understanding of the aerosol effects.

\section{Abbreviations}

AOD: Aerosol optical depth; CGCM: Coupled atmosphere-ocean global climate model; CMIP5: Coupled Model Intercomparison Project Phase 5; DJF: December, January, February; DSRS: Downward shortwave radiation at the surface; GFDL: Geophysical Fluid Dynamics Laboratory; GHG: Greenhouse gas; GPCP: Global Precipitation Climatology Project; HadCRUT4: Hadley

Centre-Climatic Research Unit Version 4; HIST: Historical experiment;

IPCC-AR5: Intergovernmental Panel on Climate Change-Fifth Assessment Report; ITCZ: Inter-tropical convergence zone; JJA: June, July, August; JRA-55: Japanese 55-year Reanalysis Project; MIROC-ESM: Model for Interdisciplinary Research on Climate-Earth System Models; piAERO: Pre-industrial aerosol experiment; SAT: Surface air temperature; SPRINTARS: Spectral

Radiation-Transport Model for Aerosol Species

\section{Acknowledgments}

This work was partly supported by the Environment Research and Technology Development Fund (S-12) of the Environmental Restoration and Conservation Agency. HGT was partly supported by the Cooperative Program of Atmosphere and Ocean Research Institute, The University of Tokyo. JRA-55 was provided by the Japan Meteorological Agency. GPCP Precipitation data were provided by the NOAA/OAR/ESRL PSD, Boulder, Colorado, USA.

\section{Funding}

This work was partly supported by the Environment Research and Technology Development Fund (S-12) of the Environmental Restoration and Conservation Agency.

\section{Availability of data and materials}

The HIST experiments are provided under the CMIP5. Please contact the authors for data requests regarding the piAERO experiments.

\section{Authors' contributions}

HGT, SW, MN, and TT proposed the topic and conceived and designed the study. WS carried out the experimental study. HGT and MN analyzed the data and SW and TT helped in their interpretation. HGT led the preparation of the manuscript. SW, MN, and TT collaborated with the corresponding author during the construction of the manuscript. All authors read and approved the final manuscript.

\section{Competing interests}

The authors declare that they have no competing interests.

\section{Publisher's Note}

Springer Nature remains neutral with regard to jurisdictional claims in published maps and institutional affiliations.

\section{Author details}

${ }^{1}$ Department of Geography, Tokyo Metropolitan University, 1-1 Minamioosawa, Hachioji, Tokyo 192-0397, Japan. ${ }^{2}$ Japan Agency for Marine-Earth Science and Technology (JAMSTEC), Yokohama, Japan. ${ }^{3}$ Kinda University, Higashiosaka, Japan. ${ }^{4}$ Research Institute for Applied Mechanics, Kyushu University, Fukuoka, Japan.

Received: 9 January 2018 Accepted: 18 July 2018

Published online: 22 August 2018

\section{References}

Adler RF, Huffman GJ, Chang A, Ferraro R, Xie P, Janowiak J, Rudolf B, Schneider U, Curtis S, Bolvin D, Gruber A, Susskind J, Arkin P, Nelkin E (2003) The version 2 Global Precipitation Climatology Project (GPCP) monthly precipitation analysis (1979-present). J Hydrometeorol 4:1147-1167

Albrecht BA (1989) Aerosols, cloud microphysics, and fractional cloudiness. Science 245(4923):1227-1230

Bollasina MA, Ming Y, Ramaswamy V (2011) Anthropogenic aerosols and the weakening of the South Asian summer monsoon. Science 334(6055):502-505. https://doi.org/10.1126/science.1204994 
Compo GP, Kiladis GN, Webster PJ (1999) The horizontal and vertical structure of east asian winter monsoon pressure surges. QJR Meteorol SoC 125(553):29-54

Fujinami H, Hatsuzuka D, Yasunari T, Hayashi T, Terao T, Murata F, Kiguchi M, Yamane Y, Matsumoto J, Islam MN, Habib A (2011) Characteristic intraseasonal oscillation of rainfall and its effect on interannual variability over Bangladesh during boreal summer. Int J Climatol 31:1192-1204. https://doi.org/10.1002/joc.2146

Golaz J-C, Salzmann M, Donner LJ, Horowitz LW, Ming Y, Zhao M (2011) Sensitivity of the aerosol indirect effect to subgrid variability in the cloud parameterization of the gfdl atmosphere general circulation model am3. J Climate 24(13):3145-3160. https://doi.org/10.1175/2010JCLI3945.1

Golaz J-C, Horowitz LW, Levy H (2013) Cloud tuning in a coupled climate model: impact on 20th century warming. Geophys Res Lett 40(10):2246-2251. https://doi.org/10.1002/grl.50232

Goswami BN, Ajaya Mohan R (2001) Intraseasonal oscillations and interannual variability of the Indian summer monsoon. J Climate 14(6):1180-1198

IPCC (2013) Climate Change 2013: The Physical Science Basis: Working Group I Contribution to the Fifth Assessment Report of the Intergovernmental Panel on Climate Change. Cambridge University Press, Cambridge

Ito M, Satomura T (2009) The interannual variation of intraseasonal oscillation linked with the Indian Ocean dipole mode. SOLA 5:69-72. https://doi.org/ 10.2151/sola.2009-018

Kiladis GN, Wheeler M (1995) Horizontal and vertical structure of observed tropospheric equatorial rossby waves. J Geophys Res 100(D1 1):22981-22997

Kobayashi S, Ota Y, Harada Y, Ebita A, Moriya M, Onoda H, Onogi K, Kamahori H, Kobayashi C, Endo H, Miyaoka K, Takahashi K (2015) The JRA-55 reanalysis: general specifications and basic characteristics. J Meteorol Soc Jpn 93(1):5-48

Lau K-M, Kim K-M (2006) Observational relationships between aerosol and Asian monsoon rainfall, and circulation. Geophys Res Lett 33(21). https:// doi.org/10.1029/2006GL027546

Lohmann U, Rotstayn L, Storelvmo T, Jones A, Menon S, Quaas J, Ekman AM, Koch D, Ruedy $\mathrm{R}$ (2010) Total aerosol effect: radiative forcing or radiative flux perturbation? Atmos Chem Phys 10:3235-3246. https://doi.org/10. 5194/acp-10-3235-2010

Michibata T, Suzuki K, Sato Y, Takemura T (2016) The source of discrepancies in aerosol-cloud-precipitation interactions between $\mathrm{gcm}$ and a-train retrievals. Atmos Chem Phys 16(23):15413-15424. https://doi.org/10.5194/ acp-16-15413-2016

Ming Y, Ramaswamy V, Ginoux PA, Horowitz LH (2005) Direct radiative forcing of anthropogenic organic aerosol. J Geophys Res 110:20208. https://doi. org/10.1029/2004JD005573

Morice CP, Kennedy JJ, Rayner NA, Jones PD (2012) Quantifying uncertainties in global and regional temperature change using an ensemble of observational estimates: The hadcrut4 data set. J Geophys Res 117(D08101). https://doi.org/10.1029/2011JD017187

Mukai M, Nakajima T, Takemura T (2008) A study of anthropogenic impacts of the radiation budget and the cloud field in East Asia based on model simulations with GCM. J Geophys Res 113:12211. https://doi.org/10.1029/ 2007JD009325

Mukai M, Nakajima T (2009) Potentiality of aerosols in changing the precipitation field in Asia. SOLA 5:97-100. https://doi.org/10.2151/sola. 2009-025

Ohara T, Akimoto H, Kurokawa J-I, Horii N, Yamaji K, Yan X, Hayasaka T (2007) An Asian emission inventory of anthropogenic emission sources for the period 1980-2020. Atmos Chem Phys 7(16):4419-4444. https://doi.org/10. 5194/acp-7-4419-2007

Penner JE, Quaas J, Storelvmo T, Takemura T, Boucher O, Guo H, Kirkevåg A, Kristjánsson JE, Seland $\varnothing$ (2006) Model intercomparison of indirect aerosol effects. Atmos Chem Phys 6(11):3391-3405. https://doi.org/10.5194/acp6-3391-2006

Ramanathan V, Chung C, Kim D, Bettge T, Buja L, Kiehl J, Washington W, Fu Q, Sikka D, Wild M (2005) Atmospheric brown clouds: impacts on South Asian climate and hydrological cycle. Proc Natl Acad Sci 102(15):5326-5333. https://doi.org/10.1073/pnas.0500656102

Salzmann M, Weser H, Cherian R (2014) Robust response of Asian summer monsoon to anthropogenic aerosols in CMIP5 models. J Geophys Res Atmos 119(19):11321-11337. https://doi.org/10.1002/2014JD021783
Shindell DT, Voulgarakis A, Faluvegi G, Milly G (2012) Precipitation response to regional radiative forcing. Atmos Chem Phys 12:6969-6982. https://doi. org/10.5194/acp-12-6969-2012

Takemura T, Okamoto H, Maruyama Y, Numaguti A, Higurashi A, Nakajima T (2000) Global three-dimensional simulation of aerosol optical thickness distribution of various origins. J Geophys Res 105(D14):17853-17873. https://doi.org/10.1029/2000JD900265

Takemura T, Nakajima T, Dubovik O, Holben BN, Kinne S (2002) Single-scattering albedo and radiative forcing of various aerosol species with a global three-dimensional model. J Climate 15(4):333-352

Takemura T, Nozawa T, Emori S, Nakajima TY, Nakajima T (2005) Simulation of climate response to aerosol direct and indirect effects with aerosol transport-radiation model. J Geophys Res 110:02202. https://doi.org/10. 1029/2004JD005029

Takahashi HG, Yasunari T (2006) A climatological monsoon break in rainfall over Indochina-a singularity in the seasonal march of the Asian summer monsoon. J Climate 19(8):1545-1556. https://doi.org/10.1175/JCLI3724.1

Takahashi HG, Fukutomi Y, Matsumoto J (2011) The impact of long-lasting northerly surges of the East Asian winter monsoon on tropical cyclogenesis and its seasonal march. J Meteor Soc Japan 89:181-200. https://doi.org/10.2151/jmsj.2011-A12

Takahashi HG, Fujinami H, Yasunari T, Matsumoto J, Baimoung S (2015) Role of tropical cyclones along the monsoon trough in the 2011 Thai flood and interannual variability. J Climate 28(4):1465-1476. https://doi.org/10.1175/ JCLI-D-14-00147.1

Takahashi C, Watanabe M (2016) Pacific trade winds accelerated by aerosol forcing over the past two decades. Nature Clim Change 6(8):768-772. https://doi.org/10.1038/nclimate2996

Taylor KE, Stouffer RJ, Meehl GA (2012) An overview of CMIP5 and the experiment design. Bull Amer Meteor Soc 93(4):485-498

Twomey SA, Piepgrass M, Wolfe T (1984) An assessment of the impact of pollution on global cloud albedo. Tellus B 36(5):356-366

van der Werf GR, Dempewolf J, Trigg SN, Randerson JT, Kasibhatla PS, Giglio L, Murdiyarso D, Peters W, Morton D, Collatz G, Dolman AJ, DeFries RS (2008) Climate regulation of fire emissions and deforestation in equatorial Asia. Proc Natl Acad Sci 105(51):20350-20355. https://doi.org/10.1073/pnas. 0803375105

Watanabe S, Hajima T, Sudo K, Nagashima T, Takcmura T, Okajima H, Nozawa T, Kawase H, Abe M, Yokohata T, Ise T, Sato H, Kato E, Takata K, Emori S, Kawamiya M (2011) MIROC-ESM 2010: model description and basic results of CMIP5-20c3m experiments. Geosci Model Dev 4:845-872

Yamaji M, Takahashi HG (2014) Asymmetrical interannual variation in aerosol optical depth over the tropics in terms of aerosol-cloud interaction. SOLA 10:185-189. https://doi.org/10.2151/sola.2014-039

\section{Submit your manuscript to a SpringerOpen ${ }^{\circ}$ journal and benefit from:}

- Convenient online submission

- Rigorous peer review

- Open access: articles freely available online

- High visibility within the field

- Retaining the copyright to your article

Submit your next manuscript at $>$ springeropen.com 